\title{
Clinical implications of coronavirus disease 2019 in neonates
}

Do-Hyun Kim, MD, PhD

Department of Pediatrics, Dongguk University Ilsan Hospital, Goyang, Korea

Since the emergence of severe acute respiratory syndrome coronavirus 2 (SARS-CoV-2) in December 2019, a small number of coronavirus disease 2019 (COVID-19) cases in neonates have been reported worldwide. Neonates currently account for only a minor proportion of the pediatric population affected by COVID-19. Thus, data on the epidemiological and clinical features of COVID-19 in neonates are limited. Approximately $3 \%$ of neonates born to mothers with COVID-19 reportedly tested positive for SARS-CoV-2. Current limited data on neonates with COVID-19 suggest that neonatal COVID-19 shows a relatively benign course despite a high requirement for mechanical ventilation. However, neonates with pre-existing medical conditions and preterm infants appear to be at a higher risk of developing severe COVID-19. The greatest perinatal concern of the COVID-19 pandemic is the possibility of vertical transmission, especially transplacental transmission of SARS$\mathrm{CoV}-2$. Although direct evidence of the vertical transmission of SARS-CoV-2 is lacking, its possibility during late pregnancy cannot be ruled out. This review summarizes available case studies on COVID-19 in neonates and introduces what is currently known about neonatal COVID-19 with focus on its vertical transmission.

Key words: COVID-19, Coronavirus, Neonate, SARS-CoV-2

\section{Key message}

- Severe acute respiratory syndrome coronavirus 2 (SARSCoV-2) was detected in approximately $3 \%$ of neonates of mothers with coronavirus disease 2019 (COVID-19).

- Neonatal COVID-19 is relatively benign with 16\%-22.4\% cases asymptomatic.

- Neonates with pre-existing medical conditions and preterm infants are at a higher risk of severe COVID-19.

- Requirement for neonatal mechanical ventilation is $20 \%$ $22.4 \%$ (vs. $4 \%$ in children)

- Low birth weight (13.9\%) and premature birth (22.2\%) affect neonates of mothers with COVID-19.

\section{Introduction}

In December 2019, a pneumonia caused by a novel coronavirus that was later named severe acute respiratory syndrome coronavirus 2 (SARS-CoV-2) emerged in Wuhan, Hubei Province, China. The outbreak of SARS-CoV-2 infection has resulted in a pandemic that has rapidly spread worldwide and has become the most serious public health threat. ${ }^{1,2)}$ Globally, as of February 1, 2021, there were more than 102 million confirmed cases of coronavirus disease 2019 (COVID-19) that caused more than 2.2 million deaths according to the World Health Organization (WHO). ${ }^{3)}$ Although numerous studies have reported on COVID-19 in adults, there is a relative paucity of data on pediatric COVID-19, particularly among neonates. To date, a small number of neonatal COVID-19 cases have been reported worldwide. Since the report of the first neonatal case on March 29, 2020, several neonatal cases of COVID-19 have been reported in Korea. ${ }^{4)}$ One of the most important concerns of neonatal COVID-19 is whether or how SARS-CoV-2 can be transmitted from the mother to the fetus. The clinical course of COVID-19 in neonates is also of great interest.

Here the author summarizes available case studies of COVID-19 in neonates and reviews what is currently known about neonatal COVID-19 with a focus on vertical transmission.

\section{Burden of COVID-19 in the pediatric population}

In Korea, as of February 1, 2021, a total of 78,508 patients had confirmed COVID-19, of whom 8,237 (10.5\%) were children aged $\leq 19$ years and 3,004 (3.8\%) were children aged $\leq 9$ years. No deaths from COVID-19 in children have been reported in Korea. $^{5)}$

In the United States (US) and globally, there are fewer cases of COVID-19 in the pediatric population than in the adult population. While children aged $0-17$ years account for $22 \%$ of the US population, recent data showed that cases of COVID-19 in children accounted for $11.1 \%$ of all COVID-19 cases in the US (as of February 1, 2021). Furthermore, COVID-19 cases in children aged $\leq 4$ years accounted for $1.9 \%$ of all confirmed

Corresponding author: Do-Hyun Kim, MD, PhD, Department of Pediatrics, Dongguk University Ilsan Hospital, 27, Dongguk-ro, Ilsandong-gu, Goyang 10326, Korea 凶Email: dayeong1@hanmail.net, https://orcid.org/0000-0002-5003-8475

Received: 26 October, 2020, Revised: 12 January, 2021, Accepted: 19 January, 2021

This is an open-access article distributed under the terms of the Creative Commons Attribution Non-Commercial License (http://creativecommons.org/licenses/bync/4.0/) which permits unrestricted non-commercial use, distribution, and reproduction in any medium, provided the original work is properly cited.

Copyright (c) 2021 by The Korean Pediatric Society 
cases of COVID-19 in the US Children with COVID-19 are less likely to develop severe illness than adults. Deaths among children due to COVID-19 accounted for less than $0.1 \%$ of total deaths in the US. ${ }^{6,7)}$ In a Chinese nationwide study, when 2,143 children with COVID-19 were classified as asymptomatic, mild, moderate, severe, and critical cases based on COVID-19 severity, infants aged $<1$ year accounted for the highest proportion $(10.6 \%)$ of severe and critical cases but the lowest proportion (1.8\%) of asymptomatic cases among all age groups. ${ }^{8)}$ Among children aged $<18$ years with COVID-19 in the US between February 12 and April 2, 2020, infants aged $<1$ year accounted for the highest proportion (62\% and 5.2\%, respectively) of hospitalizations and intensive care unit (ICU) admissions among children with COVID-19. ${ }^{9)}$ Taken together, these results suggest that infants aged $<1$ year might be at an increased risk of severe illness from COVID-19 compared to other children. However, COVID-19 severity in the neonatal group was not independently investigated in the epidemiological data from the US and China.

\section{Clinical features of COVID-19 in neonates}

Neonates currently account for only a minor proportion of the pediatric population affected by COVID-19. Thus, data on the epidemiological and clinical features of COVID-19 in neonates are limited, suggesting that neonatal COVID-19 is relatively benign despite concerns about the possibility of vertical transmission. ${ }^{10,11)}$

Among 322 neonates born to mothers with COVID-19, $10(3.1 \%)$ tested positive for SARS-CoV-2 but did not die. ${ }^{10)}$ In a literature review of 25 neonates with COVID-19 from December 2019 to April 27, 2020, cesarean section occurred in $16(64 \%)$ with a male-to-female ratio of $2.8{ }^{11)}$ The mean gestational age and birth weight of affected neonates were 37.4 weeks (range, 26.6-41.3 weeks) and 3,042 g (range, 960-4,440 g), respectively. The mean age at onset was 8.2 days (range, 1-25 days). Affected neonates manifested fever (28\%), vomiting (16\%), and cough or shortness of breath (12\%) at onset, while only $16 \%$ of affected neonates were asymptomatic. Major complications were pneumonia (12\%), respiratory distress (8\%), and sepsis (4\%). Deaths were not reported. Among all neonates with COVID-19, intensive care and mechanical ventilation were required for $32 \%$ and $20 \%$ of cases, respectively. The diagnosis of COVID-19 was made at a mean 3.1 days after admission (range, 1-15 days) mainly by reverse transcription polymerase chain reaction (RT-PCR) from nasopharyngeal swabs. RT-PCR results were negative within a mean 10.3 days after diagnosis (range, 6-17 days). ${ }^{11)}$

\section{Classification of COVID-19 in neonates}

A detailed classification system is likely to be helpful for selecting appropriate diagnostic methods and interpreting results for SARS-CoV-2 infection in neonates. A classification system and case definition of SARS-CoV-2 infection in pregnant women, fetuses, and neonates were recently proposed by Shah et al. ${ }^{12)}$ In this classification system, maternal-fetal-neonatal SARSCoV-2 infection was classified as follows: (1) maternal infection during pregnancy; (2) congenital infection with intrauterine fetal death/stillbirth; (3) congenital infection in live born neonate; (4) neonatal infection acquired intrapartum; and (5) neonatal infection acquired postpartum. Five categories were also adopted according to the likelihood of infection: (1) confirmed, (2) probable, (3) possible, (4) unlikely, and (5) not infected. The case definition of the classification system considered results of maternal and neonatal testing with the neonate's clinical status. This classification system can be revised based on additional clinical data and more reliable diagnostic tests.

\section{Summary of case studies of neonatal COVID-19}

A comprehensive literature search and review for COVID-19 in neonates in articles published between December 2019 and September 2020 was conducted by single reviewer using PubMed (National Library of Medicine, Washington DC, USA). The terms used for the literature search were "COVID-19," "SARS-CoV-2," "neonates," and "newborns." Articles in English describing SARS-CoV-2-positive neonates at $\leq 28$ days of life were included. Two extremely low gestational age neonates (ELGANs) diagnosed before 40 weeks' postmenstrual age during routine intensive neonatal care were included, although they were diagnosed after 28 days of life. Articles were excluded if they did not address demographic features, clinical features, or outcomes of neonates with COVID-19. A total of 34 articles including 49 neonates with laboratory-confirmed COVID-19 were considered eligible for review. Twelve cases (the largest number of patients) were reported in the US and 9 cases were reported in China and Italy. Details of the neonates with COVID-19 are described in Tables 1 and 2.,13-44) According to the definition by Shah et al., ${ }^{12)}$ the neonates with COVID-19 were divided into 2 groups. The first group consisted of 18 neonates diagnosed within 48 hours of life, suggesting the possibility of congenital or intrapartum infection (Table 1). The second group of 31 neonates was diagnosed after 48 hours of life; such infections were presumed to be acquired postpartum (Table 2).

The clinical features and management of neonates included in the present study are summarized in Table 3. A total of 49 neonates with COVID-19 were included. Of these, 40 (81.6\%) were term ( $\geq 37$ weeks). The youngest gestational age was 26 weeks and 4 days. The mode of delivery was available for neonates diagnosed within 48 hours of life. Cesarean section (61.1\%) was more frequent than vaginal delivery. Neonatal SARS-CoV-2 infection was more common in male infants (73.2\%). Among neonates diagnosed after 48 hours of life 
Table 1. Clinical details of 18 neonatal cases of COVID-19 diagnosed within 48 hours of life from 16 case studies

\begin{tabular}{|c|c|c|c|c|c|c|c|c|c|c|}
\hline Study & Country & No. & $\begin{array}{l}\text { RT-PCR+ } \\
\text { mother }\end{array}$ & $\begin{array}{l}\text { Gestational } \\
\text { age (wk) }\end{array}$ & $\begin{array}{l}\text { Mode of } \\
\text { delivery }\end{array}$ & Sex & $\begin{array}{l}\text { Age at initial } \\
\text { diagnosis }^{\text {a) }}\end{array}$ & $\begin{array}{l}\text { Other RT-PCR+ } \\
\text { specimens (age) }\end{array}$ & Clinical features & Managements \\
\hline Alzamora et al. ${ }^{13)}$ & Peru & 1 & + & 33 & CS & M & $16 \mathrm{hr}$ & - & Respiratory distress & MV \\
\hline Carosso et al. ${ }^{14)}$ & Italy & 1 & + & Term & VD & $\mathrm{F}$ & At birth & - & Asymptomatic & - \\
\hline Ferrazzi et al. ${ }^{15)}$ & Italy & 1 & + & Term & VD & NA & $24 \mathrm{hr}$ & - & Asymptomatic & \\
\hline Govind et al. ${ }^{16)}$ & UK & 1 & + & Term & CS & NA & NA & - & Pneumonia with fever & - \\
\hline $\begin{array}{l}\text { Gregorio-Hernández } \\
\text { et al. }^{17)}\end{array}$ & Spain & 1 & NA & Term & VD & M & & BAL (2 day) & $\begin{array}{l}\text { Underlying HIE with } \\
\text { MAS, pneumonia }\end{array}$ & MV \\
\hline \multirow[t]{3}{*}{ Kirtsman et al. ${ }^{18)}$} & Canada & 1 & + & $35^{+5}$ & CS & M & At birth & Placenta & Asymptomatic & - \\
\hline & & & & & & & & Plasma (4 day) & & \\
\hline & & - & & & & & & Stool (7 day) & & \\
\hline Kulkarni et al. ${ }^{19)}$ & India & 1 & + & Term & VD & NA & $12 \mathrm{hr}$ & $\begin{array}{l}\text { Cord stump } \\
\text { Placenta }\end{array}$ & $\begin{array}{l}\text { Fever, elevated inflam- } \\
\text { matory markers }\end{array}$ & Lopinavir/ritonavir, IVIG \\
\hline Lorenz et al. ${ }^{20)}$ & Germany & 1 & NA & Term & VD & $\mathrm{F}$ & $24 \mathrm{hr}$ & Rectum (24 hr) & $\begin{array}{l}\text { Encephalitic symptoms, } \\
\text { pneumonia }\end{array}$ & MV \\
\hline \multirow[t]{2}{*}{ Marzollo et al. ${ }^{21)}$} & Italy & 1 & + & Term & VD & M & $36 \mathrm{hr}$ & Anus (19 day) & Pneumonia & MV, hydroxychloroquine \\
\hline & & & & & & & & & Abdominal distension & \\
\hline Sinelli et al. ${ }^{22)}$ & Italy & 1 & + & Term & VD & NA & 2 day & - & Pneumonia & HFNC \\
\hline $\begin{array}{l}\text { Hinojosa-Velasco } \\
\text { et al. }{ }^{23)}\end{array}$ & Mexico & 1 & + & Term & CS & $\mathrm{F}$ & At birth & $\begin{array}{l}\text { Breastmilk/ } \\
\text { Stool ( } 4 \text { day) }\end{array}$ & Respiratory distress & LFNC \\
\hline \multirow[t]{3}{*}{ Vivanti et al. ${ }^{24)}$} & France & 1 & + & $35^{+2}$ & CS & M & $1 \mathrm{hr}$ & Placenta/AF & Encephalitic symptoms & MV \\
\hline & & & & & & & & Rectum (1 hr) & CSF: WBC 300 & \\
\hline & & & & & & & & Plasma (6 hr) & Brain MRI (+) & \\
\hline Wang et al. ${ }^{25)}$ & China & 1 & + & Term & CS & NA & $36 \mathrm{hr}$ & - & Pneumonia & - \\
\hline Zamaniyan et al. ${ }^{26)}$ & Iran & 1 & + & $32^{+4}$ & CS & $\mathrm{F}$ & 24 day & $\mathrm{AF}(24 \mathrm{hr})$ & Asymptomatic & - \\
\hline \multirow[t]{3}{*}{ Zeng et al. ${ }^{27)}$} & China & 3 & + & Term & CS & M & 2 day & Anus (2 day) & Pneumonia with fever & - \\
\hline & & & + & Term & CS & M & 2 day & Anus ( 2 day) & Pneumonia with fever & - \\
\hline & & & + & $31^{+2}$ & CS & M & 2 day & Anus ( 2 day) & Pneumonia & MV \\
\hline Zhang et al. ${ }^{28)}$ & China & 1 & + & Term & CS & M & $30 \mathrm{hr}$ & - & Respiratory distress & - \\
\hline
\end{tabular}

COVID-19, coronavirus disease 2019; RT-PCR, reverse transcription polymerase chain reaction; CS, cesarean section; MV, mechanical ventilation; VD, vaginal delivery; UK, United Kingdom; NA, not available; BAL, bronchoalveolar lavage; HIE, hypoxic ischemic encephalopathy; MAS, meconium aspiration syndrome; IVIG, intravenous immunoglobulin; HFNC, high- flow nasal cannula; LFNC, low-flow nasal cannula; AF, amniotic fluid; CSF, cerebrospinal fluid; WBC, white blood cell; MRI, magnetic resonance imaging.

a) The initial diagnosis was confirmed by testing severe acute respiratory syndrome coronavirus 2 RNA by RT-PCR using nasopharynx, oropharynx, or nasal swab specimens.

(except for the 2 ELGANs), the mean age at diagnosis was 17 days (range, 3-27 days). All neonates survived without any sequelae. Of all neonates with COVID-19, 22.4\% were asymptomatic. In a multinational multicenter cohort study performed in Europe, approximately 16\% of children with COVID-19 were asymptomatic. ${ }^{45)}$ Thus, the proportion of asymptomatic neonates $(22.4 \%)$ in the present review was slightly higher than that reported in the literature. Neonates with COVID-19 manifested fever (36.7\%), pneumonia (46.9\%), and gastrointestinal symptoms (10.2\%) including vomiting, diarrhea, and feeding intolerance. Of note, neonates with pre-existing medical conditions and preterm infants appeared to be at a higher risk of severe illness from COVID-19. Eleven neonates (22.4\%) required mechanical ventilation. Other specific treatments used included administration of lopinavir/ritonavir $(\mathrm{n}=1)$, remdesivir $(\mathrm{n}=2)$, immunoglobulin $(\mathrm{n}=2)$, and hydroxychloroquine $(n=2)$.

\section{Notable cases of neonatal COVID-19}

A case reported by Han et al. ${ }^{4}$ in Korea described viral load kinetics in multiple specimens of a neonate (the youngest) COVID-19 patient in Korea and her mother. This 27-day-old Korean female baby born at term had confirmed COVID-19 along with her mother and grandparents. The viral load of SARS-CoV-2 in the respiratory specimen of the neonate was the highest at the early stage of infection and gradually decreased with time. Notably, the viral load in the stool specimen remained high throughout her hospital stay, even after the respiratory specimens became negative. SARS-CoV-2 was also excreted at relatively low levels in the urine. These findings suggest that both stool and urine in neonates could be additional vehicles for viral transmission and that neonates with COVID-19 could have systemic complications. ${ }^{4)}$

Regarding SARS-CoV-2 infection in neonates, transmission routes other than droplets have not been confirmed. Whether and how SARS-CoV-2 can be transmitted from the mother to the fetus during pregnancy remains unclear. Vivanti et al. ${ }^{24)}$ 
Table 2. Clinical details of 31 neonatal cases of COVID-19 diagnosed after 48 hours of life from 20 case studies

\begin{tabular}{|c|c|c|c|c|c|c|c|c|c|}
\hline Study & Country & No. & $\begin{array}{l}\text { RT-PCR+ } \\
\text { mother }\end{array}$ & $\begin{array}{l}\text { Gestational } \\
\text { age (wk) }\end{array}$ & Sex & $\begin{array}{c}\text { Age at initial } \\
\text { diagnosis } \\
(\text { day })^{\text {a) }}\end{array}$ & $\begin{array}{l}\text { Other RT-PCR+ } \\
\text { specimens (age) }\end{array}$ & Clinical features & Managements \\
\hline Aghdam et al. ${ }^{29)}$ & Iran & 1 & NA & Term & M & 15 & - & Fever, respiratory distress & LFNC \\
\hline $\begin{array}{l}\text { Chacón-Aguilar } \\
\text { et al. }{ }^{30)}\end{array}$ & Spain & 1 & NA & Term & M & 26 & - & Seizure, fever, diarrhea & - \\
\hline Buosenso et al. ${ }^{31)}$ & Italy & 1 & + & Term & NA & 15 & - & Asymptomatic & - \\
\hline Cook et al. ${ }^{32)}$ & UK & 1 & - & $27 w k$ & M & 56 & - & Pneumonia, septic shock & MV, remdesivir \\
\hline \multirow[t]{3}{*}{ Dima et al. ${ }^{33)}$} & Romania & 3 & + & Term & M & 16 & - & Asymptomatic & - \\
\hline & & & + & Term & M & 10 & - & Fever & - \\
\hline & & & + & Term & $\mathrm{F}$ & 17 & - & Pneumonia with fever & IVIG \\
\hline \multirow[t]{2}{*}{ Ferrazzi et al. ${ }^{15)}$} & Italy & 2 & + & Term & NA & 3 & - & Asymptomatic & \\
\hline & & & + & Term & NA & 3 & - & $\begin{array}{l}\text { Respiratory and gastrointestinal } \\
\text { symptoms }\end{array}$ & MV \\
\hline Han et al. ${ }^{4)}$ & Korea & 1 & + & Term & $\mathrm{F}$ & 27 & $\begin{array}{l}\text { Stool/saliva/plasma/ } \\
\text { urine ( } 27 \text { day) }\end{array}$ & Fever, cough, vomiting & - \\
\hline \multirow{2}{*}{$\begin{array}{l}\text { Gregorio-Hernández } \\
\text { et al. }{ }^{17)}\end{array}$} & Spain & 2 & NA & $28 w k$ & M & 78 & - & Underlying BPD, Pneumonia & LFNC \\
\hline & & & NA & Term & M & 6 & - & Pneumonia & - \\
\hline Mehta et al. ${ }^{34)}$ & USA & 1 & + & $28 w k$ & $\mathrm{~F}$ & 3 & - & Asymptomatic & - \\
\hline Munoz et al. ${ }^{35)}$ & USA & 1 & NA & Term & M & 21 & - & Pneumonia & $\begin{array}{c}\text { MV, } \\
\text { hydroxychloroquine }\end{array}$ \\
\hline Paret et al. ${ }^{36)}$ & USA & 1 & NA & Term & $M$ & 25 & - & Pneumonia with fever & - \\
\hline Patek et al. ${ }^{37)}$ & USA & 1 & NA & Term & $M$ & 14 & - & Pneumonia with fever & LFNC \\
\hline Piersigilli et al. ${ }^{38)}$ & Belgium & 1 & + & $26^{+4} \mathrm{wk}$ & $\mathrm{F}$ & 7 & - & Pneumonia & MV \\
\hline Precit et al. ${ }^{39)}$ & USA & 1 & + & Term & M & 10 & - & Pneumonia & HFNC \\
\hline Salik et al. ${ }^{40)}$ & USA & 1 & + & Term & $\mathrm{F}$ & 7 & - & Underlying TOF, pneumonia & MV \\
\hline \multirow[t]{2}{*}{ Salvatori et al. ${ }^{41)}$} & Italy & 2 & + & Term & M & 18 & - & Asymptomatic & - \\
\hline & & & + & Term & $\mathrm{F}$ & 10 & - & Cough, diarrhea, poor feeding & - \\
\hline Sun et al. ${ }^{42)}$ & China & 1 & + & Term & M & 6 & - & Asymptomatic & - \\
\hline \multirow[t]{4}{*}{ Wardell et al. ${ }^{43)}$} & USA & 4 & - & Term & M & 19 & - & $\begin{array}{l}\text { Pneumonia with fever } \\
\text { Mild systolic dysfunction }\end{array}$ & LFNC, remdesivir \\
\hline & & & NA & Term & M & 24 & - & Pneumonia with fever & LFNC \\
\hline & & & NA & Term & M & 21 & - & Irritability, poor feeding & - \\
\hline & & & NA & Term & M & 21 & - & Fever, cough & - \\
\hline \multirow[t]{2}{*}{ White et al. ${ }^{44)}$} & USA & 2 & + & Term & M & 17 & - & Pneumonia with fever & LFNC \\
\hline & & & + & Term & M & 27 & - & Pneumonia with fever & LFNC \\
\hline \multirow[t]{3}{*}{ Zhang et al. ${ }^{28)}$} & China & 3 & + & Term & $M$ & 17 & - & Fever, cough, vomiting & - \\
\hline & & & + & Term & $M$ & 5 & - & Fever & - \\
\hline & & & + & Term & $\mathrm{F}$ & 5 & - & Asymptomatic & - \\
\hline
\end{tabular}

COVID-19, coronavirus disease 2019; RT-PCR, reverse transcript polymerase chain reaction; NA, not available; LFNC, low-flow nasal cannula; UK, United Kingdom; IVIG, intravenous immunoglobulin; MV, mechanical ventilation; BPD, bronchopulmonary dysplasia; USA, United States of America; HFNC, high-flow nasal cannula; TOF, tetralogy of Fallot.

a)The initial diagnosis was confirmed by testing severe acute respiratory syndrome coronavirus 2 RNA by RT-PCR using nasopharynx, oropharynx, or nasal swab specimens.

demonstrated a neonatal case of SARS-CoV-2 through vertical or transplacental transmission. Such vertical transmission following maternal viremia, placental infection, and neonatal viremia was confirmed by comprehensive virological and pathological investigations. The viral load of SARS-CoV- 2 in the placental tissue was much higher than that in any other specimen such as the maternal and neonatal blood. A placental histological examination revealed placental inflammation. Remarkably, the neonate presented with symptoms such as irritability, poor feeding, hypertonia, and opisthotonus. Encephalitic symptoms are very rare in neonates but commonly observed in adult patients. ${ }^{20)}$ Kirtsman et al. ${ }^{18)}$ and Kulkarni et al. ${ }^{19)}$ also demon- strated placental infection of SARS-CoV-2 in two neonates with COVID-19. According to the definition by Shah et al., ${ }^{12)}$ the case reported by Kirtsman et al. ${ }^{18)}$ represents a probable case of congenital SARS-CoV-2 infection in live born neonates, and the case reported by Vivanti et al. ${ }^{24)}$ represents a confirmed case of congenital SARS-CoV-2 infection in a live born neonate.

\section{Vertical transmission of SARS-CoV-2}

To date, it is believed that neonatal COVID-19 is mostly caused by horizontal transmission of SARS-CoV-2 through 
Table 3. Summary of clinical details of neonatal COVID-19 described in case studies

\begin{tabular}{|c|c|c|c|}
\hline Variable & $\begin{array}{l}\text { Diagnosis } \\
\text { within } 48 \mathrm{hr} \\
\text { of life } \\
(n=18)\end{array}$ & $\begin{array}{c}\text { Diagnosis } \\
\text { after } 48 \mathrm{hr} \text { of } \\
\text { life } \\
(\mathrm{n}=31)\end{array}$ & $\begin{array}{l}\text { Total } \\
(n=49)\end{array}$ \\
\hline \multicolumn{4}{|l|}{ Gestational age (wk) } \\
\hline Term (>37) & $13(72.2)$ & $27(87.1)$ & $40(81.6)$ \\
\hline $34-36$ & $2(11.1)$ & $0(0)$ & $2(4.1)$ \\
\hline$<34$ & $3(16.7)$ & $4(12.9)$ & $7(14.3)$ \\
\hline CS delivery & $11(61.1)$ & - & - \\
\hline Male sex & 9/13 (69.2) & $21 / 28(71.4)$ & $30 / 41(73.2)$ \\
\hline $\begin{array}{l}\text { Initial RT-PCR(+) (DOL), } \\
\text { mean (range) }\end{array}$ & - & $17(3-27)^{a}$ & - \\
\hline \multicolumn{4}{|l|}{ Clinical features } \\
\hline Asymptomatic & $4(22.2)$ & $7(22.6)$ & $11(22.4)$ \\
\hline Fever & $4(22.2)$ & $14(45.2)$ & $18(36.7)$ \\
\hline Pneumonia & $9(50.0)$ & $14(45.2)$ & $23(46.9)$ \\
\hline Gastrointestinal symptoms & $1(5.6)$ & $4(12.9)$ & $5(10.2)$ \\
\hline \multicolumn{4}{|l|}{ Treatments } \\
\hline Mechanical ventilator & $6(33.3)$ & $5(16.1)$ & $11(22.4)$ \\
\hline High-flow nasal cannula & $1(5.6)$ & $1(3.2)$ & $2(4.1)$ \\
\hline Low-flow nasal cannula & $1(5.6)$ & $7(22.6)$ & $8(16.3)$ \\
\hline Lopinavir/ritonavir & $1(5.6)$ & $0(0)$ & $1(2.0)$ \\
\hline Remdesivir & $0(0)$ & $2(6.5)$ & $2(4.1)$ \\
\hline IVIG & $1(5.6)$ & $1(3.2)$ & $2(4.1)$ \\
\hline Hydroxychloroquine & $1(5.6)$ & $1(3.2)$ & $2(4.1)$ \\
\hline
\end{tabular}

Values are presented as number (\%) unless otherwise indicated.

COVID-19, coronavirus disease 2019; CS, cesarean section; RT-PCR, reverse transcription polymerase chain reaction; DOL, days of life; IVIG, intravenous immunoglobulin.

a) Two extremely low gestational age neonates diagnosed after 28 days of life were excluded.

close contact with an infected person, usually his/her parent. The vertical transmission of SARS-CoV-2 can occur via transplacental transmission, intrapartum, or breastfeeding. Currently, the greatest concern in perinatal aspects of the COVID-19 pandemic is the possibility of vertical, especially transplacental, transmission of SARS-CoV-2. Vertical transmission has not been reported in either SARS or Middle East respiratory syndrome. Based on these findings, the possibility of vertical transmission of SARSCoV-2 was thought to be very low in the early pandemic. ${ }^{46,47)}$ In a study detecting SARS-CoV-2 from different types of clinical specimens of 205 patients with COVID-19, only 1\% (3 of 307) of blood specimens tested positive for RT-PCR, suggesting that placental and fetal seeding from maternal blood might be quite rare. ${ }^{48)}$

The first retrospective review of the possibility of vertical transmission of SARS-CoV-2 during pregnancy was reported in China. In 9 neonates born to 9 mothers with confirmed COVID-19 pneumonia, all samples collected from conception and the neonates, such as amniotic fluid, cord blood, neonatal throat swabs, and breastmilk tested negative for SARS-CoV-2. ${ }^{49}$ ) Another Chinese study described 2 neonatal cases born to mothers with COVID-19 during the third trimester. Serial RT-PCR assays also failed to detect SARS-CoV-2 in neonatal nasopharyngeal swabs, maternal serum, placental tissues, cord blood, amniotic fluid, vaginal swabs, and breastmilk. ${ }^{50)}$

However, several subsequent studies have suggested the possibility of vertical transmission. A cohort study described 33 neonates born to mothers with COVID-19, including 3 neonates with COVID-19.27) The nasopharyngeal and anal swabs in these 3 neonates tested positive for SARS-CoV- 2 on days 2 and 4 of life. The authors suggested that SARS-CoV-2 in these neonates' upper respiratory tracts and anuses is likely to have originated from their mothers, indicating that the vertical transmission of SARS-CoV-2 cannot be ruled out. ${ }^{27)}$ More recently, a neonate born to a mother with COVID-19 reportedly had elevated levels of SARS-CoV-2 immunoglobulin M (IgM), immunoglobulin G (IgG), and interleukin-6 2 hours after birth, with negative RTPCR results for nasopharyngeal swabs taken from 2 hours to 16 days after birth. The RT-PCR results of the mother's vaginal secretions and breastmilk were negative. ${ }^{51)}$ Elevated SARSCoV-2 IgM and IgG levels in 2 neonates of mothers infected by COVID-19 with negative RT-PCR results for throat swabs and blood samples of neonates have also been reported. ${ }^{52)}$ However, the role of serology in the diagnosis of SARS-CoV-2 infection remains uncertain. Serologic findings in these 3 neonates are not evidence of a true congenital infection, but rather could represent an artifact. ${ }^{53}$

Angiotensin-converting enzyme 2 (ACE2) is known to play essential roles in infection and transmission as a receptor of SARS-CoV-2. ${ }^{54)}$ Based on the online available single-cell RNA sequencing database, ACE2 has very low expression in the placenta during the first trimester of pregnancy. ${ }^{55)}$ However, one study of fetal and postnatal mouse lung tissue revealed that the ACE2 level changes dynamically over time, peaking in neonatal mice at postnatal days $1-3 .{ }^{54)}$ Together with 2 cases of congenital SARS-CoV-2 infection, these laboratory data suggest that transplacental transmission during late pregnancy could indeed be possible. ${ }^{18,24)}$

Laboratory and clinical findings to date can be summarized as shown below. First, direct evidence of the vertical transmission of SARS-CoV-2 is still lacking. Second, the possibility of vertical transmission during the third trimester of gestation cannot be ruled out. Third, the possible transmission of SARS-CoV-2 during early pregnancy and subsequent fetal outcomes remain unknown.

\section{Transmission of SARS-CoV-2 via breastmilk}

Although SARS-CoV-2 RNA has been detected in breastmilk in several studies, the majority of studies have not demonstrated SARS-CoV- 2 in breastmilk. ${ }^{56-58)}$ In a recent observational cohort study, all 64 neonates breastfed by mothers with COVID-19 who undertook correct hygiene precautions tested negative for SARS-CoV-2 at 5-7 days and 14 days of life. ${ }^{59)}$ It remains unclear whether mothers with COVID-19 can transmit the virus via breastmilk. Current limited data suggest that it is unlikely. ${ }^{60)}$ 


\section{Perinatal outcomes of pregnant women with COVID-19}

In the early COVID-19 pandemic, there were no comparative studies that determined whether pregnancy might be a risk factor for severe COVID-19.61) One report from the WHO-China Joint Mission on COVID-19 concluded that pregnant women are not at a higher risk of developing severe disease due to COVID-19 than nonpregnant women. ${ }^{62)}$ However, subsequent studies revealed that pregnant women with COVID-19 might experience more severe disease. ${ }^{63,64)}$

From January 22 to June 7, 2020, the Centers for Disease Control and Prevention in the US analyzed the data of 91,412 women of reproductive age (15-44 years) with confirmed COVID-19 and for whom pregnancy status data were available. ${ }^{63)}$ Among them, 8,207 (9.0\%) were pregnant. After adjusting for confounding factors, the authors found that pregnant women with COVID-19 were 5.4 times more likely to be hospitalized, 1.5 times more likely to be admitted to an ICU, and 1.7 times more likely to require mechanical ventilation than nonpregnant women with COVID-19. However, the risk of death was not significantly different between pregnant and nonpregnant women. This nationwide study shows that pregnant women and their families should be counseled about the potential risk of severe disease due to COVID-19.63)

A retrospective case-control study in China reported outcomes of neonates born to mothers with COVID-19. ${ }^{64)}$ In that study, from January 24 to February 29, 2020, neonatal outcomes of 36 pregnant women with COVID-19 pneumonia were compared with those of 121 pregnant women without COVID-19 admitt. ed during the same period (2020 control group) and 121 women admitted between January 24 and February 11, 2019 (2019 control group). The results showed that rates of low birth weight (13.9\%) and premature birth (22.2\%) among neonates born to mothers with COVID-19 were significantly higher than those in the 2 control groups (2.5\% and 5.4\%, respectively). ${ }^{64)}$ Although data on outcomes of patients with maternal and neonatal COVID-19 are still limited, pregnant women and their neonates might be at increased risk for developing severe COVID-19 and experiencing unfavorable birth outcomes.

\section{Conclusion}

The limited evidence available suggests a very low incidence and a relatively benign course of COVID-19 in neonates. Although a significant proportion of neonates in the present study required ventilator care, those with COVID-19 generally showed good outcomes without mortality. However, the sample sizes of studies of neonates with COVID-19 were too small to determine the risk of neonatal COVID-19. Despite the lack of direct evidence, there is growing concern about the risk of vertical transmission of SARS-CoV-2. Further research on the epidemiology, pathophysiology, and diagnosis of the vertical transmission of SARS-CoV-2 is urgently required.

\section{Conflicts of interest}

No potential conflict of interest relevant to this article was reported.

\section{Acknowledgments}

The author is grateful for the support of the members of the Korean Society of Neonatology and Pediatric Infectious Diseases.

\section{References}

1. Zhu N, Zhang D, Wang W, Li X, Yang B, Song J, et al. A novel coronavirus from patients with pneumonia in China, 2019. N Engl J Med 2020; 382:727-33.

2. Huang C, Wang Y, Li X, Ren L, Zhao J, Hu Y, et al. Clinical features of patients infected with 2019 novel coronavirus in Wuhan, China. Lancet 2020;395:497-506.

3. World Health Organization. WHO Coronavirus Disease (COVID-19) Dashboard [Internet]. Geneva (Switzerland): World Health Organization; 2021 [cited $2021 \mathrm{Feb} 2$ ]. Available from: https://covid19.who.int/.

4. Han MS, Seong MW, Heo EY, Park JH, Kim N, Shin S, et al. Sequential analysis of viral load in a neonate and her mother infected with SARSCoV-2. Clin Infect Dis 2020;71:2236-9.

5. Korea Disease Control and Prevention Agency. Coronavirus Disease-19 in Republic of Korea, as of 1 February, 2021. Cheongju (Korea): Korea Disease Control and Prevention Agency; 2021 [cited 2021 Feb 2]. Available from: http://ncov.mohw.go.kr/.

6. Centers for Disease Control and Prevention. Coronavirus disease 2019 (COVID-19): Information for Pediatric Healthcare Providers [Internet]. Atlanta (GA): US Department of Health Services, CDC; 2020 [cited 2020 Oct 10]. Available from: https://www.cdc.gov/coronavirus/2019-ncov/ hcp/pediatric-hcp.html.

7. Centers for Disease Control and Prevention. Coronavirus disease 2019 (COVID-19): CDC COVID Data Tracker [Internet]. Atlanta (GA): US Department of Health Services, CDC; 2021 [cited 2021 Feb 2]. Available from: https://covid.cdc.gov/covid-data-tracker/\#demographics.

8. Dong Y, Mo X, Hu Y, Qi X, Jiang F, Jiang Z, et al. Epidemiology of COVID-19 among children in China. Pediatrics 2020;145:e20200702.

9. CDC COVID-19 Response Team. Coronavirus Disease 2019 in children - United States, February 12-April 2, 2020. MMWR Morb Mortal Wkly Rep 2020;69:422-6.

10. Rozycki HJ, Kotecha S. Covid-19 in pregnant women and babies: what pediatricians need to know. Paediatr Respir Rev 2020;35:31-7.

11. De Bernardo G, Giordano M, Zollo G, Chiatto F, Sordino D, De Santis $\mathrm{R}$, et al. The clinical course of SARS-CoV-2 positive neonates. J Perinatol 2020;40:1462-9.

12. Shah PS, Diambomba Y, Acharya G, Morris SK, Bitnun A. Classification system and case definition for SARS-CoV-2 infection in pregnant women, fetuses, and neonates. Acta Obstet Gynecol Scand 2020;99:565-8.

13. Alzamora MC, Paredes T, Caceres D, Webb CM, Valdez LM, La Rosa M. Severe COVID-19 during pregnancy and possible vertical transmission. Am J Perinatol 2020;37:861-5.

14. Carosso A, Cosma S, Borella F, Marozio L, Coscia A, Ghisetti V, et al. Prelabor anorectal swab for SARS-CoV-2 in COVID-19 pregnant patients: is it time to think about it? Eur J Obstet Gynecol Reprod Biol 2020;249:989.

15. Ferrazzi E, Frigerio L, Savasi V, Vergani P, Prefumo F, Barresi S, et al. Vaginal delivery in SARS-CoV-2-infected pregnant women in Northern Italy: a retrospective analysis. BJOG 2020;127:1116-21.

16. Govind A, Essien S, Karthikeyan A, Fakokunde A, Janga D, Yoong W, et al. Re: Novel Coronavirus COVID-19 in late pregnancy: outcomes of first 
nine cases in an inner city London hospital. Eur J Obstet Gynecol Reprod Biol 2020;251:272-4

17. Gregorio-Hernandez R, Escobar-Izquierdo AB, Cobas-Pazos J, MartínezGimeno A. Point-of-care lung ultrasound in three neonates with COVID-19. Eur J Pediatr 2020;179:1279-85.

18. Kirtsman M, Diambomba Y, Poutanen SM, Malinowski AK, Vlachodimitropoulou E, Parks WT, et al. Probable congenital SARS$\mathrm{CoV}-2$ infection in a neonate born to a woman with active SARS-CoV-2 infection. CMAJ 2020;192:E647-50.

19. Kulkarni R, Rajput U, Dawre R, Valvi C, Nagpal R, Magdum N, et al. Early-onset symptomatic neonatal COVID-19 infection with high probability of vertical transmission. Infection 2020 Aug 2:1-5. [Epub]. https://doi.org/10.1007/s15010-020-01493-6.

20. Lorenz N, Treptow A, Schmidt S, Hofmann R, Raumer-Engler M, Heubner G, et al. Neonatal early-onset infection with SARS-CoV-2 in a newborn presenting with encephalitic symptoms. Pediatr Infect Dis J 2020;39:e212.

21. Marzollo R, Aversa S, Prefumo F, Saccani B, Perez CR, Sartori E, et al. Possible coronavirus disease 2019 pandemic and pregnancy: vertical transmission is not excluded. Pediatr Infect Dis J 2020;39:e261-2.

22. Sinelli M, Paterlini G, Citterio M, Di Marco A, Fedeli T, Ventura ML. Early neonatal SARS-CoV-2 infection manifesting with hypoxemia requiring respiratory support. Pediatrics 2020;146:e20201121.

23. Hinojosa-Velasco A, de Oca PVB, García-Sosa LE, Mendoza-Duran JG, Perez-Mendez MJ, Davila-Gonzalez E, et al. A case report of newborn infant with severe COVID-19 in Mexico: detection of SARS-CoV-2 in human breast milk and stool. Int J Infect Dis 2020;100:21-4.

24. Vivanti AJ, Vauloup-Fellous C, Prevot S, Zupan V, Suffee C, Do Cao J, et al. Transplacental transmission of SARS-CoV-2 infection. Nat Commun 2020;11:3572.

25. Wang S, Guo L, Chen L, Liu W, Cao Y, Zhang J, et al. A case report of neonatal 2019 coronavirus disease in China. Clin Infect Dis 2020;71:8537.

26. Zamaniyan M, Ebadi A, Aghajanpoor S, Rahmani Z, Haghshenas M, Azizi S. Preterm delivery, maternal death, and vertical transmission in a pregnant woman with COVID-19 infection. Prenat Diagn 2020;40: 1759-61.

27. Zeng L, Xia S, Yuan W, Yan K, Xiao F, Shao J, et al. Neonatal earlyonset infection with SARS-CoV-2 in 33 neonates born to mothers with COVID-19 in Wuhan, China. JAMA Pediatr 2020;174:722-5.

28. Zhang ZJ, Yu XJ, Fu T, Liu Y, Jiang Y, Yang BX, et al. Novel coronavirus infection in newborn babies aged $<28$ days in China. Eur Respir J 2020; 55:2000697.

29. Aghdam MK, Jafari N, Eftekhari K. Novel coronavirus in a 15-dayold neonate with clinical signs of sepsis, a case report. Infect Dis (Lond) 2020;52:427-9.

30. Chacón-Aguilar R, Osorio-Cámara JM, Sanjurjo-Jimenez I, GonzálezGonzález C, López-Carnero J, Pérez-Moneo B. COVID-19: fever syndrome and neurological symptoms in a neonate. An Pediatr (Barc) 2020;92:373-4.

31. Buonsenso D, Costa S, Sanguinetti M, Cattani P, Posteraro B, Marchetti S, et al. Neonatal late onset infection with severe acute respiratory syndrome coronavirus 2. Am J Perinatol 2020;37:869-72.

32. Cook J, Harman K, Zoica B, Verma A, D'Silva P, Gupta A. Horizontal transmission of severe acute respiratory syndrome coronavirus 2 to a premature infant: multiple organ injury and association with markers of inflammation. Lancet Child Adolesc Health 2020;4:548-51.

33. Dima M, Enatescu I, Craina M, Petre I, Iacob ER, Iacob D. First neonates with severe acute respiratory syndrome coronavirus 2 infection in Romania: three case reports. Medicine (Baltimore) 2020;99:e21284.

34. Mehta H, Ivanovic S, Cronin A, VanBrunt L, Mistry N, Miller R, et al. Novel coronavirus-related acute respiratory distress syndrome in a patient with twin pregnancy: a case report. Case Rep Womens Health 2020;27:e00220.

35. Munoz AC, Nawaratne U, McMann D, Ellsworth M, Meliones J, Boukas K. Late-onset neonatal sepsis in a patient with Covid-19. N Engl J Med 2020;382:e49.
36. Paret M, Lighter J, Pellett Madan R, Raabe VN, Shust GF, Ratner AJ. SARS-CoV-2 infection (COVID-19) in febrile infants without respiratory distress. Clin Infect Dis 2020;71:2243-5.

37. Patek P, Corcoran J, Adams L, Khandhar P. SARS-CoV-2 infection in a 2-week-old male with neutropenia. Clin Pediatr (Phila) 2020;59:918-20.

38. Piersigilli F, Carkeek K, Hocq C, van Grambezen B, Hubinont C, Chatzis O, et al. COVID-19 in a 26-week preterm neonate. Lancet Child Adolesc Health 2020;4:476-8.

39. Precit MR, Yee R, Anand V, Mongkolrattanothai K, Pandey U, Dien Bard J. A case report of neonatal acute respiratory failure due to severe acute respiratory syndrome coronavirus-2. J Pediatric Infect Dis Soc 2020;9:390-2.

40. Salik I, Mehta B. Tetralogy of Fallot palliation in a COVID-19 positive neonate. J Clin Anesth 2020;66:109914.

41. Salvatori G, De Rose DU, Concato C, Alario D, Olivini N, Dotta A, et al. Managing COVID-19-positive maternal-infant dyads: an Italian experience. Breastfeed Med 2020;15:347-8.

42. Sun M, Xu G, Yang Y, Tao Y, Pian-Smith M, Madhavan V, et al. Evidence of mother-to-newborn infection with COVID-19. Br J Anaesth 2020;125:e245-7.

43. Wardell H, Campbell JI, VanderPluym C, Dixit A. SARS-CoV-2 infection in febrile neonates. J Pediatric Infect Dis Soc 2020;9:630-5.

44. White A, Mukherjee P, Stremming J, Sherlock LG, Reynolds RM, Smith $\mathrm{D}$, et al. Neonates hospitalized with community-acquired SARS-CoV-2 in a Colorado neonatal intensive care unit. Neonatology 2020;117:641-5.

45. Gotzinger F, Santiago-Garcia B, Noguera-Julian A, Lanaspa M, Lancella L, Calo Carducci FI, et al. COVID-19 in children and adolescents in Europe: a multinational, multicentre cohort study. Lancet Child Adolesc Health 2020;4:653-61.

46. Rasmussen SA, Smulian JC, Lednicky JA, Wen TS, Jamieson DJ. Coronavirus disease 2019 (COVID-19) and pregnancy: what obstetricians need to know. Am J Obstet Gynecol 2020;222:415-26.

47. Schwartz DA, Graham AL. Potential maternal and infant outcomes from (Wuhan) Coronavirus 2019-nCoV infecting pregnant women: lessons from SARS, MERS, and other human coronavirus infections. Viruses 2020;12:194.

48. Wang W, Xu Y, Gao R, Lu R, Han K, Wu G, et al. Detection of SARSCoV-2 in different types of clinical specimens. JAMA 2020;323:1843-4.

49. Chen H, Guo J, Wang C, Luo F, Yu X, Zhang W, et al. Clinical characteristics and intrauterine vertical transmission potential of COVID-19 infection in nine pregnant women: a retrospective review of medical records. Lancet 2020;395:809-15.

50. Fan C, Lei D, Fang C, Li C, Wang M, Liu Y, et al. Perinatal transmission of COVID-19 associated SARS-CoV-2: should we worry? Clin Infect Dis 2021;72:862-4.

51. Dong L, Tian J, He S, Zhu C, Wang J, Liu C, et al. Possible vertical transmission of SARS-CoV-2 from an infected mother to her newborn. JAMA 2020;323:1846-8.

52. Zeng H, Xu C, Fan J, Tang Y, Deng Q, Zhang W, et al. Antibodies in infants born to mothers with COVID-19 pneumonia. JAMA 2020;323:1848-9.

53. Kimberlin DW, Stagno S. Can SARS-CoV-2 infection be acquired in utero? More definitive evidence is needed. JAMA 2020;323:1788-9.

54. Li M, Chen L, Zhang J, Xiong C, Li X. The SARS-CoV-2 receptor ACE2 expression of maternal-fetal interface and fetal organs by single-cell transcriptome study. PLoS One 2020;15:e230295.

55. Zheng QL, Duan T, Jin LP. Single-cell RNA expression profiling of ACE2 and AXL in the human maternal-fetal interface. Reprod Dev Med 2020;4:7-10.

56. Groß R, Conzelmann C, Muller JA, Stenger S, Steinhart K, Kirchhoff F, et al. Detection of SARS-CoV-2 in human breastmilk. Lancet 2020;395: 1757-8.

57. Wu Y, Liu C, Dong L, Zhang C, Chen Y, Liu J, et al. Coronavirus disease 2019 among pregnant Chinese women: case series data on the safety of vaginal birth and breastfeeding. BJOG 2020;127:1109-15.

58. American Academy of Pediatrics. FAQs: Managements of Infants Born to Mothers with Suspected of Confirmed COVID-19 [Internet]. Itasca (IL): American Academy of Pediatrics; 2020 [cited 2020 Oct 10]. Available 
from: https://services.aap.org/en/pages/2019-novel-coronavirus-covid-19infections/clinical-guidance/faqs-management-of-infants-born-to-covid19-mothers/.

59. Salvatore CM, Han JY, Acker KP, Tiwari P, Jin J, Brandler M, et al. Neonatal management and outcomes during the COVID-19 pandemic: an observation cohort study. Lancet Child Adolesc Health 2020;4:721-7.

60. Centers for Disease Control and Prevention. Coronavirus disease 2019 (COVID-19): Coronavirus Disease (COVID-19) and Breastfeeding [Internet]. Atlanta (GA): US Department of Health Services, CDC; 2020 [cited 2020 Oct 10]. Available from: https://www.cdc.gov/breastfeeding/ breastfeeding-special-circumstances/maternal-or-infant-illnesses/covid19-and-breastfeeding.html.

61. Mimouni F, Lakshminrusimha S, Pearlman SA, Raju T, Gallagher PG, Mendlovic J. Perinatal aspects on the covid-19 pandemic: a practical resource for perinatal-neonatal specialists. J Perinatol 2020;40:820-6.

62. World Health Organization. Report of the WHO-China Joint Mission on Coronavirus Disease 2019 (COVID-19) [Internet]. Geneva (Switzer- land): World Health Organization; 2020 [cited 2020 Oct 10]. Available from: https://www.who.int/docs/default-source/coronaviruse/who-chinajoint-mission-on-covid-19-final-report.pdf.

63. Ellington S, Strid P, Tong VT, Woodworth K, Galang RR, Zambrano $\mathrm{LD}$, et al. Characteristics of women of reproductive age with laboratoryconfirmed SARS-CoV-2 infection by pregnancy status - United States, January 22-June 7, 2020. MMWR Morb Mortal Wkly Rep 2020;69: 769-75.

64. Li N, Han L, Peng M, Lv Y, Ouyang Y, Liu K, et al. Maternal and neonatal outcomes of pregnant women with COVID-19 pneumonia: a casecontrol study. Clin Infect Dis 2020;71:2035-41.

How to cite this article: Kim DH. Clinical implications of coronavirus disease 2019 in neonates. Clin Exp Pediatr 2021;64:157-64. https://doi.org/10.3345/cep.2020.01795 